\title{
Effect of Superdisintegrants on Dissolution of Cationic Drugs
}

\author{
J. Balasubramaniam ${ }^{1,4}$, K. Bindu1 , V. U. Rao' , D. Ray ${ }^{2}$, R. Haldar ${ }^{2}$, \\ and A.W.Brzeczko ${ }^{3}$ \\ e-mail:jbalasubramaniam@ispcorp.com \\ ${ }^{1}$ International Specialty Products (India) Pvt. Ltd., H. No 6-3-1090/A, Bhupal Towers, Rajbhavan Road, Somajiguda, Hyderabad - 500 082, \\ INDIA \\ ${ }^{2}$ International Specialty Products, 1361 Alps Road, Wayne, NJ 07470 \\ ${ }^{3}$ ISP Pharma Systems LLC, 9176 Red Branch Road, Columbia, MD 21045
}

\begin{abstract}
The effects of selected superdisintegrants on the dissolution behavior of several cationic drugs with varying water solubility were evaluated. All formulations were made with fixed disintegrant concentration and equal drug load using a model formulation. Tablets were made by direct compression and were compressed to equal hardness. Dissolution studies were carried out in dissolution media specified in the compendium (USP) or in media recommended by the U.S. Food and Drug Administration (FDA) for the respective actives. The effect of media pH on the dissolution of drugs was also evaluated.

The use of crospovidone significantly improved the dissolution of the cationic drugs in the model formulation when compared with the other superdisintegrants studied. The compendial or the FDA recommended media, in most cases, was able to discriminate among the tablets containing different superdisintegrants.

Crospovidone can be effectively used as a tablet disintegrant to improve the dissolution of either soluble or poorly soluble cationic drugs.
\end{abstract}

\section{INTRODUCTION}

$\mathrm{n}$ spite of the increased focus and interest generated in the area of controlled release and targeted drug delivery system in recent years, tablet dosage forms that are intended to be swallowed whole, disintegrate, and release their medicaments rapidly in the gastrointestinal tract still remain the formulation of choice from both a manufacturing as well as a patient acceptability point of view. Thus, a drug given in the form of a tablet must undergo dissolution before being absorbed and eventually transported into systemic circulation. For most of the tablet dosage forms, disintegration precedes drug dissolution. Superdisintegrants (1) such as croscarmellose sodium, sodium starch glycolate (SSG), and crospovidone are now frequently used in tablet formulations to improve the rate and extent of tablet disintegration and thus improve the rate of drug dissolution.

The behavior of superdisintegrants in various tablet formulations has been investigated by many researchers (2-6). The majority of this research has been directed at the function-related properties of the superdisintegrants with special emphasis on correlating these properties to disintegrant efficiency and drug release.

The research focus in recent years has shifted to the formulation of both fast dissolving or disintegrating tablets that are swallowed and tablets that are intended to dissolve in the oral cavity (7-9). However, some research has also focused on using substantially higher amounts of superdisintegrants with the aim of either improving the dissolution or stabilizing the formulations $(10,11)$.

${ }^{4}$ Corresponding author.
The choice of superdisintegrant for a tablet formulation depends largely on the nature of the drug being used. For example, the solubility of the drug component could affect the rate and mechanism of tablet disintegration. Water-soluble materials tend to dissolve rather than disintegrate, while insoluble materials generally tend to disintegrate if an appropriate amount of disintegrant is included in the formulation (6).

Furthermore, the ionic nature of the drug and superdisintegrants and their potential interactions have been reported to affect the dissolution of tablet formulations (12-14). Of the commonly used superdisintegrants, crospovidone is nonionic, while SSG and croscarmellose sodium are anionic. It has been proposed that any weakly basic (cationic) drug, when present in an environment where the $\mathrm{pH}$ is $>2$ and near or below the $\mathrm{pK}_{\mathrm{a}}$ of the cationic drug, should be expected to interact with ionized polymers like croscarmellose sodium and SSG (13). Further, in an in vitro dissolution test conducted by using a fixed amount of distilled water, the drug-excipient interaction could result in a decreased or apparent incomplete drug release from the dosage form. In an earlier study (14), it was reported that dissolution of phenylpropanolamine $\mathrm{HCl}$ from tablets containing croscarmellose sodium showed only $60 \%$ of apparent amount of drug released, while the release from the corresponding control tablet (without any disintegrant) and a tablet with pregelatinized starch as the disintegrant showed almost complete release. However, this interaction did not adversely influence the bioavailability of phenylpropanolamine in human subjects.

In these earlier studies demonstrating drug-excipient interactions in dissolution media, many of the cationic 
drugs were of moderate to high aqueous solubility. However, many new or recently discovered cationic drugs are poorly water soluble. Thus in the present study, an attempt has been made to investigate the effect of various tablet superdisintegrants on the dissolution behavior of some model cationic drugs having varying degrees of aqueous solubility. For convenience, the drugs used were classified broadly as soluble drugs (cetirizine $\mathrm{HCl}$, ranitidine $\mathrm{HCl}$, venlafaxine $\mathrm{HCl}$, and chlorpromazine $\mathrm{HCl}$ ) and poorly soluble drugs (ciprofloxacin $\mathrm{HCl}$, fexofenadine $\mathrm{HCl}$, terbinafine $\mathrm{HCl}$, and clopidogrel bisulfate).

\section{MATERIALS AND METHODS}

Cetirizine $\mathrm{HCl}$ (Glochem Industries Ltd., Hyderabad, India), fexofenadine $\mathrm{HCl}$ and terbinafine (Aurobindo Pharma Ltd., Hyderabad, India), ciprofloxacin $\mathrm{HCl}$ (Dr. Reddy's Laboratories, Hyderabad, India), ranitidine $\mathrm{HCl}$ (Orchev Pharma Pvt. Ltd., Rajkot, India), chlorpromazine $\mathrm{HCl}$ and clopidogrel bisulfate (Emco Industries, Hyderabad), and venlafaxine $\mathrm{HCl}$ (Amoli Organics Pvt. Ltd. Vapi, India) were purchased from the sources indicated. Croscarmellose sodium (Ac-di-sol ${ }^{\circledR}$, FMC Biopolymer) and SSG (GLYCOLYS ${ }^{\circledR}$, Roquette) were purchased from Signet (India). Polyplasdone ${ }^{\circledR}$ XL crospovidone was provided by International Specialty Products (ISP). All other reagents were of analytical grade.

\section{Preparation of Tablets}

The general formula of the tablets is given in Table 1. The required quantities of the ingredients were weighed and blended to form a homogenous powder mix. The blends were then compressed on 12.5-mm flat-faced, beveled-edged punch set on a Rotary Compression machine (Cadmach, 16-station, Ahmedabad, India) at 550 mg theoretical weight and at approximately equal hardness. AIM software (MCC, NJ) was used to determine the compression force required to yield tablets of approximately equal hardness for the various drugs used in the study.

\section{Breaking Force Determination}

The breaking force of the prepared tablets was determined $24 \mathrm{~h}$ after compression using Erweka hardness tester (Erweka TBH 310 MD), which also

\section{Table 1. General Formula of the Prepared Tablets.}

\begin{tabular}{lcc}
\hline Ingredient & Weight \% per tablet & mg per tablet \\
\hline Active drug & 18 & 100 \\
\hline Superdisintegrant & 2 & 10 \\
\hline Magnesium stearate & 0.5 & 2.5 \\
\hline Talc & 0.5 & 2.5 \\
\hline Avicel pH 102 & q.s. 100 & 435 \\
\hline
\end{tabular}

measures the diameter of the tablets. Ten tablets from each batch were tested for tablet strength, and the mean and standard deviation were calculated.

\section{Disintegration Time}

Disintegration times of the prepared tablets were measured in $900 \mathrm{~mL}$ of purified water with disc at $37^{\circ} \mathrm{C}$ using Erweka TAR series tester. Disintegration times of six individual tablets were recorded.

\section{In Vitro Dissolution Studies}

The dissolution studies of the prepared tablets were carried out using USP Apparatus 2 (Vankel VK). A peristaltic pump was coupled to a Cary 50 UV-vis spectrophotometer to provide a continuous flow of drug solution through 1-cm cuvettes. Dissolution was performed in $0.1 \mathrm{~N} \mathrm{HCl}(\mathrm{pH} 1.2), \mathrm{pH} 4.5$ acetate buffer, and $\mathrm{pH} 7.2$ phosphate buffer $\left(900 \mathrm{~mL}\right.$ each) at $37 \pm 0.5^{\circ} \mathrm{C}$ at the paddle speed recommended for each drug in the compendium. In addition, the profiling was performed using the compendial or FDA recommended medium of the respective drugs if it was different from the ones already used. Furthermore, if the $\mathrm{pH}$ of the compendial or recommended medium was within $\pm 1.5 \mathrm{pH}$ units of the above-mentioned three media, then dissolution was only carried out in the compendial or FDA recommended medium for that particular $\mathrm{pH}$ range. Samples were programmed to be analyzed at 5, 10, 15, 30, 45, and $60 \mathrm{~min}$ at the $\lambda_{\max }$ of the respective drugs. The time required for $80 \%$ of drug to be released $\left(t_{80}\right)$ was considered for comparing the dissolution results. The $t_{80}$ was determined by fitting the dissolution data to a four-parametric logistic model using the Marquardt-Levenberg algorithm (Sigmaplot 9.0 SPSS Inc., Chicago, IL).

$$
y=\min +\frac{\max -\min }{1+10^{\left[\operatorname{logEC} C_{50}-x\right] \times \text { hillslope }}}
$$

In this equation, $y$ represents the Cumulative \% drug released, $x$ is the time in minutes, $\min$ is the baseline of $\%$ drug released at 0 min, $\max$ is the plateau of $\%$ drug released at $60 \mathrm{~min}$, and hillslope is the slope of the curve at transition center $E C_{50}$.

\section{RESULTS AND DISCUSSION}

The objective of the present study was to investigate the effect of nonionic and anionic superdisintegrants on the dissolution behavior of cationic drugs with varying aqueous solubilities. The chemical structures of the superdisintegrants and the different drugs used in the present study are shown in Figures 1-3. Accordingly, crospovidone, specifically Polyplasdone $\mathrm{XL}$, was compared with croscarmellose sodium and SSG.

The breaking force and the disintegration times of the prepared tablets are shown in Table 2 . Relatively equal tablet hardness values are shown for all tablets of the model drug with the various superdisintegrants; thus 
<smiles>CC(C)CCN1CCCC1=O</smiles>

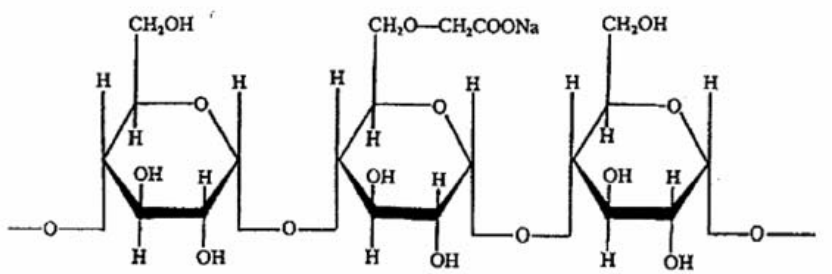

(b)

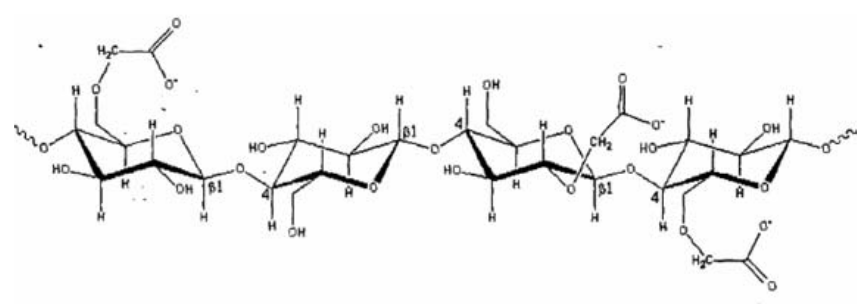

(c)

Figure 1. Chemical structures of disintegrants used in the study: (a) Polyplasdone XL crospovidone; (b) sodium starch glycolate; and (c) croscarmellose sodium.<smiles>CN(C)CCN1c2ccccc2Sc2ccc(Cl)cc21</smiles>

(a)

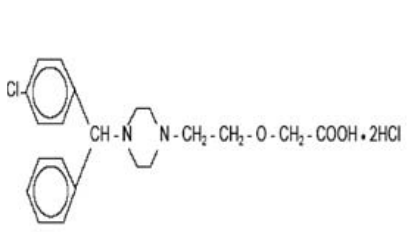

(c)<smiles>CCc1ccc(CCNC(=O)NC)o1</smiles>

(b)

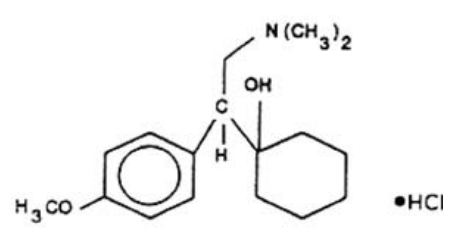

(d)
Figure 2. Chemical structures of water-soluble cationic drugs used in the study: (a) chlorpromazine, (b) ranitidine $\mathrm{HCl}$, (c) cetirizine $\mathrm{HCl}$, (d) venlafaxine $\mathrm{HCl}$.

disintegration time variability due to tablet hardness effects was minimal. No differences were observed in the disintegration times of the tablets prepared using the various superdisintegrants for the drugs studied. Based on equal disintegration times, model drug release from the respective tablets should relate solely to the drug dissolution rate and not the rate of tablet disintegration. Notably, the disintegration times of the soluble cationic drugs were higher than those of the poorly soluble cationic drugs, except for cetirizine $\mathrm{HCl}$.

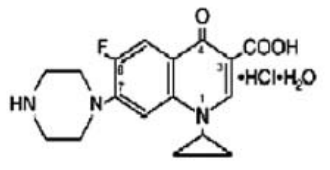

(a)<smiles>CN(C/C=C/C#CC(C)(C)C)Cc1cccc2ccccc12</smiles>

(c)

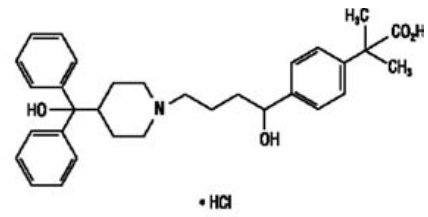

(b)

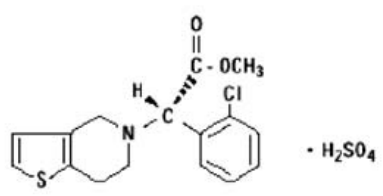

(d)
Figure 3. Chemical structures of poorly soluble cationic drugs used in the study: (a) ciprofloxacin $\mathrm{HCl}$, (b) fexofenadine $\mathrm{HCl}$, (c) terbinafine, (d) clopidogrel bisulfate.

Table 2. Hardness and Disintegration Time (DT) for the Prepared Tablets.

\begin{tabular}{|c|c|c|c|}
\hline Drug & Superdisintegrant & Hardness (N) & DT (min) \\
\hline \multirow[t]{3}{*}{ Ciprofloxacin } & Croscarmellose sodium & $182 \pm 4$ & $4.5 \pm 0.3$ \\
\hline & SSG & $187 \pm 6$ & $3.5 \pm 0.3$ \\
\hline & Polyplasdone XL & $190 \pm 4$ & $4.0 \pm 0.4$ \\
\hline \multirow[t]{3}{*}{ Fexofenadine } & Croscarmellose sodium & $180 \pm 5$ & $4.5 \pm 0.3$ \\
\hline & SSG & $176 \pm 6$ & $3.5 \pm 0.3$ \\
\hline & Polyplasdone XL & $181 \pm 6$ & $4.0 \pm 0.3$ \\
\hline \multirow[t]{3}{*}{ Terbinafine } & Croscarmellose sodium & $158 \pm 5$ & $3.5 \pm 0.4$ \\
\hline & SSG & $149 \pm 5$ & $4.0 \pm 0.4$ \\
\hline & Polyplasdone XL & $163 \pm 5$ & $4.5 \pm 0.4$ \\
\hline \multirow[t]{3}{*}{ Clopidogrel bisulfate } & Croscarmellose sodium & $156 \pm 6$ & $4.0 \pm 0.6$ \\
\hline & SSG & $160 \pm 5$ & $4.5 \pm 0.5$ \\
\hline & Polyplasdone XL & $161 \pm 5$ & $3.5 \pm 0.5$ \\
\hline \multirow[t]{3}{*}{ Chlorpromazine } & Croscarmellose sodium & $158 \pm 5$ & $9.0 \pm 0.5$ \\
\hline & SSG & $149 \pm 6$ & $9.5 \pm 0.5$ \\
\hline & Polyplasdone XL & $163 \pm 6$ & $10.0 \pm 0.4$ \\
\hline \multirow[t]{3}{*}{ Ranitidine } & Croscarmellose sodium & $183 \pm 5$ & $10.0 \pm 0.5$ \\
\hline & SSG & $178 \pm 5$ & $11.0 \pm 0.6$ \\
\hline & Polyplasdone XL & $189 \pm 5$ & $10.5 \pm 0.5$ \\
\hline \multirow[t]{3}{*}{ Cetirizine } & Croscarmellose sodium & $180 \pm 5$ & $4.0 \pm 0.5$ \\
\hline & SSG & $179 \pm 6$ & $3.0 \pm 0.6$ \\
\hline & Polyplasdone XL & $182 \pm 6$ & $3.5 \pm 0.5$ \\
\hline \multirow[t]{3}{*}{ Venlafaxine } & Croscarmellose sodium & $174 \pm 6$ & $8.5 \pm 0.5$ \\
\hline & SSG & $181 \pm 7$ & $8.0 \pm 0.4$ \\
\hline & Polyplasdone XL & $178 \pm 6$ & $8.5 \pm 0.4$ \\
\hline
\end{tabular}


For the water-soluble cationic drugs studied, the compendial dissolution medium for ranitidine $\left(\mathrm{pK}_{\mathrm{a}}\right.$ of 8.2), cetirizine ( $\mathrm{pK}_{\mathrm{a}}$ of 8.3), and venlafaxine ( $\mathrm{pK}_{\mathrm{a}}$ of 9.4) is water, while for chlorpromazine ( $\mathrm{pK}_{\mathrm{a}}$ of 9.3) it is $0.1 \mathrm{~N} \mathrm{HCl}(\mathrm{pH} 1.2)$. The $t_{80}$ data (Table 3 and Figure 4) show that drug release from tablets of ranitidine, cetirizine, and venlafaxine containing croscarmellose sodium and SSG was slower than from the corresponding tablets containing Polyplasdone XL. This is consistent with a previous study (14) wherein the drug-excipient interaction was observed for the cationic drug phenylpropanolamine and the anionic disintegrant croscarmellose in its compendial dissolution media, which is also water. When water is the dissolution medium, raniditine, cetirizine, and venlafaxine demonstrate a greater interaction with the anionic disintegrants, because fewer counterions are present in water. A similar trend was also observed for chlorpromazine; drug release in $\mathrm{pH} 1.2$ (compendial medium) from tablets containing croscarmellose sodium and SSG was slower than from corresponding tablets containing Polyplasdone XL. For these drugs, perhaps a higher affinity for the anionic disintegrants is favored even in the presence of competing ions.

For poorly soluble drugs, $t_{80}$ release (Table 4 and Figure 5) was not achieved for any of the drugs (except ciprofloxacin $\mathrm{HCl}$ ) with any of the superdisintegrants in any medium other than the compendial or recommended

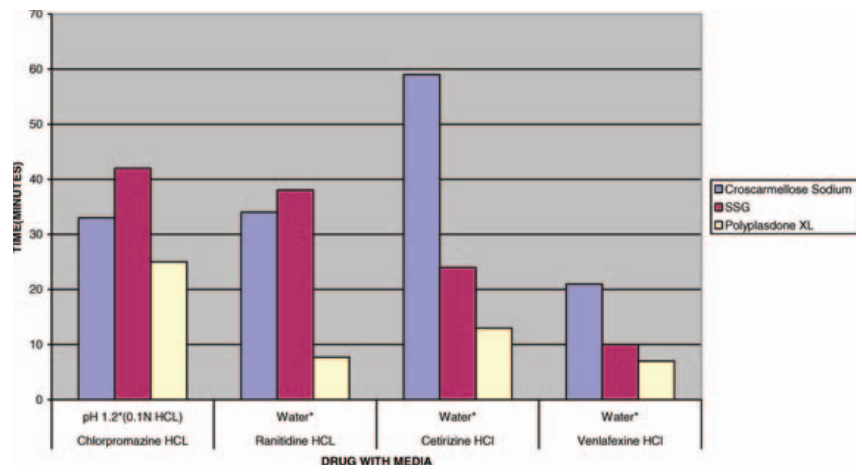

Figure 4. $T_{80}$ of water-soluble cationic drugs in respective compendial media.

medium. This could be attributed to the lack of aqueous solubility of these drugs, rather than to the nature of the superdisintegrants used. In the case of clopidogrel, tablets containing Polyplasdone XL showed the fastest release in the compendial medium ( $\mathrm{pH}$ 2.0). However, the release was only marginally faster than that from tablets containing croscarmellose. In comparison, fexofenadine $\mathrm{HCl}\left(\mathrm{pK}_{\mathrm{a}}\right.$ of 9.53) tablets with Polyplasdone $\mathrm{XL}$ reached $80 \%$ release $1.5-2$ times faster than tablets containing other disintegrants.

In the case of terbinafine $\mathrm{HCl}\left(\mathrm{pK}_{\mathrm{a}}\right.$ of 7.1), only tablets with Polyplasdone XL were able to achieve $80 \%$ release in

Table 3. $T_{80}$ Values of Water-Soluble Cationic Drugs in Different Dissolution Media.

\begin{tabular}{|c|c|c|c|c|c|c|c|}
\hline \multirow[b]{2}{*}{ DRUG } & \multirow[b]{2}{*}{$\begin{array}{l}\text { DISSOLUTION } \\
\text { MEDIUM }\end{array}$} & \multicolumn{3}{|c|}{$\mathbf{T}_{80}(\min )$} & \multicolumn{3}{|c|}{$R^{2}$ values of the fit } \\
\hline & & $\begin{array}{l}\text { Croscarmellose } \\
\text { sodium }\end{array}$ & SSG & $\begin{array}{c}\text { Polyplasdone } \\
\text { XL }\end{array}$ & $\begin{array}{l}\text { Croscarmellose } \\
\text { sodium }\end{array}$ & SSG & $\begin{array}{c}\text { Polyplasdone } \\
\text { XL }\end{array}$ \\
\hline \multirow[t]{3}{*}{ Chlorpromazine $\mathrm{HCl}$} & $\mathrm{pH} 1.2^{*}$ & $32.63 \pm 1.4$ & $41.87 \pm 2.2$ & $25.04 \pm 1.3$ & 0.997 & 0.995 & 0.995 \\
\hline & $\mathrm{pH} 4.5$ & $27.33 \pm 1.6$ & $28.72 \pm 2.3$ & $25.61 \pm 1.6$ & 0.992 & 0.992 & 0.997 \\
\hline & $\mathrm{pH} 7.2$ & $44.75 \pm 2.2$ & $54.43 \pm 2.1$ & $38.35 \pm 1.8$ & 0.991 & 0.992 & 0.997 \\
\hline \multirow[t]{4}{*}{ Ranitidine $\mathrm{HCl}$} & $\mathrm{pH} 1.2$ & $1.19 \pm 0.5$ & $2.78 \pm 0.7$ & $5.41 \pm 0.14$ & 0.995 & 0.994 & 0.998 \\
\hline & $\mathrm{pH} 4.5$ & $17.32 \pm 2.5$ & $38.79 \pm 2.6$ & $1.12 \pm 0.1$ & 0.994 & 0.995 & 0.997 \\
\hline & $\mathrm{pH} 7.2$ & $4.53 \pm 2.3$ & $6.42 \pm 2.8$ & $3.55 \pm 0.59$ & 0.993 & 0.996 & 0.993 \\
\hline & Water* & $33.86 \pm 1.2$ & $38.19 \pm 2.5$ & $7.67 \pm 0.12$ & 0.994 & 0.994 & 0.995 \\
\hline \multirow[t]{4}{*}{ Cetirizine $\mathrm{HCl}$} & $\mathrm{pH} 1.2$ & $45.39 \pm 2.2$ & $33.94 \pm 2.4$ & $12.84 \pm 2.2$ & 0.993 & 0.996 & 0.995 \\
\hline & $\mathrm{pH} 4.5$ & $60.65 \pm 2.5$ & $43.85 \pm 2.5$ & $22.49 \pm 2.6$ & 0.991 & 0.995 & 0.994 \\
\hline & $\mathrm{pH} 7.2$ & $52.44 \pm 2.3$ & $31.43 \pm 1.9$ & $22.54 \pm 2.4$ & 0.992 & 0.995 & 0.997 \\
\hline & Water* & $59.02 \pm 2.1$ & $24.31 \pm 2.0$ & $12.76 \pm 2.5$ & 0.993 & 0.995 & 0.996 \\
\hline \multirow[t]{4}{*}{ Venlafaxine $\mathrm{HCl}$} & $\mathrm{pH} 1.2$ & $9.06 \pm 0.8$ & $8.83 \pm 0.9$ & $7.59 \pm 0.56$ & 0.994 & 0.995 & 0.995 \\
\hline & $\mathrm{pH} 4.5$ & $4.89 \pm 0.2$ & $2.84 \pm 0.4$ & $3.22 \pm 0.45$ & 0.996 & 0.995 & 0.992 \\
\hline & $\mathrm{pH} 7.2$ & $11.41 \pm 2.3$ & $8.58 \pm 0.6$ & $10.64 \pm 2.3$ & 0.991 & 0.995 & 0.996 \\
\hline & Water* & $20.97 \pm 2.5$ & $10.37 \pm 2.3$ & $6.95 \pm 0.25$ & 0.992 & 0.995 & 0.994 \\
\hline
\end{tabular}

*Compendial recommended medium 
Table 4. $T_{80}$ Values of Poorly Water Soluble Cationic Drugs in Different Dissolution Media.

\begin{tabular}{|c|c|c|c|c|c|c|c|}
\hline \multirow[b]{2}{*}{ DRUG } & \multirow[b]{2}{*}{$\begin{array}{l}\text { DISSOLUTION } \\
\text { MEDIUM }\end{array}$} & \multicolumn{3}{|c|}{$\mathbf{T}_{80}(\min )$} & \multicolumn{3}{|c|}{$R^{2}$ values of the fit } \\
\hline & & $\begin{array}{l}\text { Croscarmellose } \\
\text { sodium }\end{array}$ & SSG & $\begin{array}{c}\text { Polyplasdone } \\
\text { XL }\end{array}$ & $\begin{array}{l}\text { Croscarmellose } \\
\text { sodium }\end{array}$ & SSG & $\begin{array}{c}\text { Polyplasdone } \\
\text { XL }\end{array}$ \\
\hline \multirow[t]{4}{*}{ Ciprofloxacin $\mathrm{HCl}$} & $\mathrm{pH} 1.2^{*}$ & $32.68 \pm 1.2$ & $24.69 \pm 2.3$ & $21.18 \pm 2.2$ & 0.998 & 0.993 & 0.994 \\
\hline & $\mathrm{pH} 4.5$ & $16.45 \pm 1.5$ & $22.35 \pm 2.5$ & $15.81 \pm 2.4$ & 0.993 & 0.995 & 0.995 \\
\hline & $\mathrm{pH} 7.2$ & $19.31 \pm 1.6$ & $12.23 \pm 1.5$ & $9.89 \pm 1.2$ & 0.995 & 0.991 & 0.997 \\
\hline & water & $59.06 \pm 2.0$ & $60.03 \pm 2.2$ & $24.32 \pm 1.3$ & 0.994 & 0.995 & 0.997 \\
\hline Fexofenadine $\mathrm{HCl}$ & $\begin{array}{c}\mathrm{pH} 1.2 \\
(0.001 \mathrm{~N} \mathrm{HCl})^{*}\end{array}$ & $28.64 \pm 2.6$ & $23.36 \pm 2.6$ & $14.1 \pm 1.5$ & 0.996 & 0.993 & 0.996 \\
\hline \multirow[t]{2}{*}{ Terbinafine $\mathrm{HCl}$} & $\mathrm{pH} 3$ & NA & $11.18 \pm 2.8$ & $0.57 \pm 0.02$ & 0.992 & 0.997 & 0.998 \\
\hline & $\mathrm{pH} 3(500 \mathrm{~mL})^{*}$ & NA & NA & $32.47 \pm 1.7$ & 0.994 & 0.991 & 0.994 \\
\hline Clopidogrel bisulfate & $\mathrm{pH} 2.0^{*}$ & $9.92 \pm 0.25$ & $14.64 \pm 2.1$ & $9.77 \pm 2.2$ & 0.992 & 0.993 & 0.995 \\
\hline
\end{tabular}

*Compendial recommended medium.

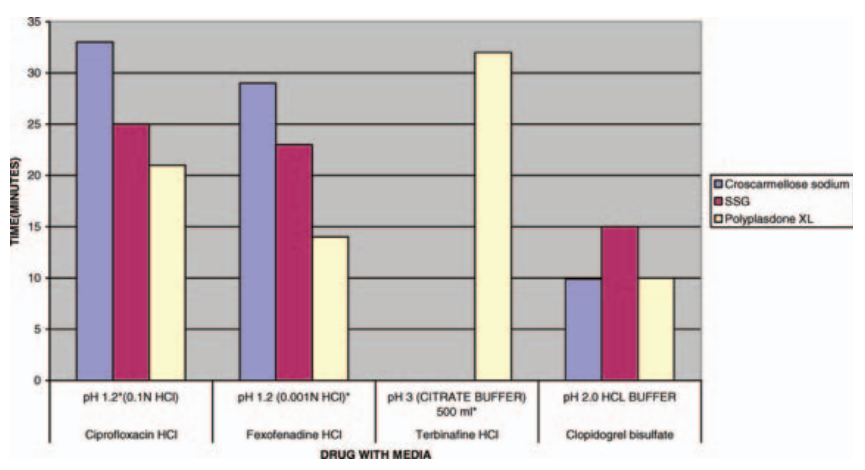

Figure $5 . T_{80}$ of poorly soluble cationic drugs in the respective compendial media.

the compendial medium ( $\mathrm{pH} 3$ citrate buffer, $500 \mathrm{~mL}$ ). When the volume of the dissolution medium was increased to $900 \mathrm{~mL}$, tablets with SSG also managed $80 \%$ release. However, tablets with Polyplasdone $\mathrm{XL}$ achieved $80 \%$ release in less than 1 min. Better sink conditions, owing to the increase in volume of the dissolution media, could be attributed for the faster release. However, the increase in volume did not favor drug release from tablets containing croscarmellose sodium, suggesting that the level of croscarmellose sodium used in the study ( $2 \% \mathrm{w} / \mathrm{w})$ may not be adequate to improve the dissolution of terbinafine. Polyplasdone $\mathrm{XL}$ gave faster release for ciprofloxacin $\mathrm{HCl}\left(\mathrm{pK}_{\mathrm{a}}\right.$ of 8.7) in all the media studied.

The overall results point to the fact that crospovidone is more effective in enhancing the dissolution rate of the drugs studied, irrespective of their aqueous solubilities, and the compendial medium was able to discriminate among the formulations. This trend was even more notable with the poorly soluble drugs. Since it is nonionic, crospovidone does not interact with the cationic drug moiety, unlike the anionic disintegrants croscarmellose sodium and SSG.

\section{CONCLUSION}

In this study, a comprehensive evaluation of the dissolution rates of cationic drugs with varying water solubility was performed. The effectiveness of superdisintegrants in model tablet formulations was shown. In general, crospovidone and, more specifically, Polyplasdone $\mathrm{XL}$ demonstrated a more rapid dissolution rate for the model cationic drugs, irrespective of their aqueous solubilities. Since Polyplasdone crospovidone is a nonionic disintegrant, no ionic interaction occurs between it and the cationic drugs.

Furthermore, the compendial medium was able to discriminate between the tablets containing different superdisintegrants in most cases studied. In the case of three water-soluble cationic drugs, ranitidine, cetirizine and venlafaxine, where water is the compendial medium, Polyplasdone $\mathrm{XL}$ had the fastest $t_{80}$ results. In cases where water provides sink conditions ( $\leq 25 \%$ maximum drug solubility), water is a preferred compendial medium. However, ionic interaction between cationic drugs and anionic superdisintegrants may delay drug release to such an extent as to fail the $\mathrm{Q}$ tolerance of the compendial dissolution method for this product. Although this ionic interaction did not have a biological impact for phenylpropanolamine, this may not be the case for all cationic drugs. In the excipient selection process, formulation screening of superdisintegrants to minimize dissolution retardation from drug-excipient interaction is recommended. In addition, the $\mathrm{r}^{2}$ values ranged between 0.991 and 0.998 (Tables 3 and 4), suggesting that the four-parameter logistic model provided a reasonably good fit for determining $t_{80}$. 


\section{References}

1. Shangraw, R.; Mitrevej, A.; Shah, M. Pharm. Technol. 1980, 4, 49-57.

2. Gordon, M.S.; Rudraraju, V. S.; Dani, K.; Chowhan, A.T. Effect of mode of superdisintegrant Incorporation on dissolution in wet granulated tablets. J. Pharm. Sci. 1993, 82 (2), 220-226.

3. Zhao, N.; Augsburger, L. L. The influence of swelling capacity of superdisintegrants in different $\mathrm{pH}$ media on the dissolution of hydrochlorothiazide from directly compressed tablets. AAPS PharmSciTech 2005, 6 (1), E120-E126.

4. Zhao, N.; Augsburger, L. L. The influence of granulation on superdisintegrant performance. Pharm. Dev. Technol. 2006, 11,47-53.

5. Zhao, N.; Augsburger, L. L. Functionality Comparison of 3 Classes of Superdisintegrants in Promoting Aspirin Tablet Disintegration and Dissolution. AAPS PharmSciTech. 2005, 6 (4), E634-E640.

6. Johnson, J.R.;Wang, L. H.; Gordon, M.S.; Chowhan, Z.T. Effect of formulation solubility and hygroscopicity on disintegrating efficiency in tablets prepared by wet granulation. J. Pharm. Sci. 1991, 80,469-471.

7. Bi, Y.X.; Sunanda, H.; Yonezawa, Y.; Danjo, K. Evaluation of rapidly disintegrating tablets prepared by a direct compression method. Drug Dev. Ind. Pharm. 1999, 25, $571-581$.
8. Sallam, E.; Ibrahim, H.; Abu Dahab, R.; Shubair, M.; Khalil, E. Evaluation of fast disintegrants in terfenadine tablets containing a gas-evolving disintegrant. Drug Dev. Ind. Pharm. 1999, 24, 501-507.

9. Bi, Y.; Sunanda, H.; Yonezawa, Y. Preparation and evaluation of a compressed tablet rapidly disintegrating in the oval cavity. Chem. Pharm. Bull. 1996, 44, 2121-2127.

10. Dietrich, R.; Ney, H. Oral-administration forms of a medicament containing pantoprazol. U.S. Patent 5,997,903, Dec 7, 1999.

11. Michael, M.; Dorossiev, I. Stable pharmaceutical compositions containing 7-substituted-3,5dihydroxyheptanoic acids or 7-substituted-3,5dihydroxyheptenoic acids. U.S. Pat. 6,558,659, May 6, 2003.

12. Chien, Y.W.; Van Nostrand, P.; Hurwitz, A. R.; Shami, E.G.Drug-disintegrant interactions: binding of oxymorphone derivatives. J.Pharm. Sci. 1981, 70, 709-710.

13. Hollenbeck, R. G.; Mitrevej, K.T.; Fan, A. C. Estimation of the extent of drug-excipient interactions involving croscarmellose sodium.J. Pharm. Sci. 1983, 72, 325-327.

14. Hollenbeck, R. G. Bioavailability of phenylpropanolamine $\mathrm{HCl}$ from tablet dosage forms containing croscarmellose sodium. Int. J. Pharm. 1988, 47, 89-93. 